\title{
In praise of soft science
}

\section{'Hard' scientists should stop looking down their noses at social scientists, and instead share methods that could help them address pressing societal problems.}

$$
\mid \begin{aligned}
& \mathrm{t} \\
& \mathrm{en}
\end{aligned}
$$

$t$ is the conventional wisdom in the biological and physical sciences, and within research agencies, that the social sciences are, well, 'soft', and lacking in methodological rigour. That's why it is arresting that the US National Science Foundation's prestigious Alan T. Waterman award for young scientists has gone this year to Dalton Conley, a sociologist at New York University (see page 1024).

Conley specializes in the detailed study of economic outcomes among underprivileged groups, and says he avoids research on attitudes because they can't be measured accurately. Research agencies in the United States and elsewhere need to support more social scientists like him, because their work can potentially make a valuable contribution to the study of important societal problems.

Take, for example, climate change and biodiversity loss, two global environmental problems for which human behaviour is a significant driver. Research on these issues tends to focus on the physical nature of the phenomena in question. Study of whatever underlies the behaviour itself is too often regarded as 'soft' science and dismissed as second-rate.

Or consider the relationship between biomedical research and public health. The United States has constructed a well-funded and carefully calibrated system to research and develop the best pharmaceuticals and medical equipment that modern science can provide. But what good is that if patients don't take their drugs correctly, or pharmacists routinely misread a doctor's handwriting? A 1999 US Institute of Medicine study found that medical errors - human errors - kill as many as 98,000 people every year, more than the number who die from traffic accidents, breast cancer or HIV/AIDS. Shouldn't psychology and sociologybe better harnessed to address this problem?

Even when social science is confident in its assertions, it often feels that it gets no respect from the outside world. Writing in the current issue of the American Sociological Association magazine Contexts, for example, Harold Wilensky, a political scientist at the University of California, Berkeley, says that social scientists have identified specific, practical solutions for problems such as crime prevention and access to health care. But their advice is largely ignored by US policy-makers, Wilensky argues, adding that governments in northern Europe and Japan have a better track record of implementing social scientists' findings.

It can be argued, of course, that social scientists have brought much of this upon themselves. A lot of their work is politically contentious by its very nature, and the spread of what can be loosely termed 'relativism' has reduced their clout. With so many gifted amateurs working their territory, social scientists have a tougher time asserting the unique nature of their expertise than do astrophysicists, for example. Few of us know much about the dynamics of the cosmos, but we all know plenty about human nature - or at least we think we do.

So the onus falls on the social scientists themselves to hone their methods and ensure that they are ready to stand up to external scrutiny. The National Science Foundation has recognized the need to strengthen methodology in the social sciences. Since the terrorist attacks of 11 September 2001, it has also, to its credit, devoted considerable effort to increasing the resources available to its directorate of social, behavioural and economic sciences.

On the campuses, meanwhile, 'hard' scientists need to get over their disdain for their 'soft' colleagues. The study of society can't just be left to poets and politicians. As the almost boundless complexity of physical and biological systems becomes increasingly apparent, along with the pressing need to better understand patterns of human behaviour, now is as good at time as any for a rapprochement between the two wings of the scientific academy.

\section{Not-so-deep impact}

\section{Research assessment rests too heavily on the inflated status of the impact factor.}

E very year at the end of June, scientific publishers' eyes turn to Philadelphia, where the Institute for Scientific Information (ISI) releases a snippet of data that they crave: the impact factor of each journal. In due course, bureaucrats in research agencies will roll the impact figures into their performance indicators, and those scientists who worry about such things will quietly note which journal's number wins them the most brownie points.

Attempts to quantify the quality of science are always fraught with difficulty, and the journal impact factors are among the few numbers to persist. The result is an overemphasis of what is really a limited metric.

To obtain the latest impact factors, which were released last week, the ISI number-crunchers added the total number of citations from all the monitored journals during 2004 to items in the journal of interest that were published in 2002 and 2003 . They then divided that total by the number of 'citable items' - loosely, papers and review articles - that were published in the journal during those same two years.

The impact factor is taken by some administrators as a measure of the typical citation rate for the journal. But for many journals, it isn't 'typical' at all. Nature's latest impact factor is 32.2 , an increase on last year and a high number that we're proud of, but it's one that merits a closer look.

For example, we have analysed the citations of individual papers 
in Nature and found that $89 \%$ of last year's figure was generated by just $25 \%$ of our papers.

The most cited Nature paper from 2002-03 was the mouse genome, published in December 2002. That paper represents the culmination of a great enterprise, but is inevitably an important point of reference rather than an expression of unusually deep mechanistic insight. So far it has received more than 1,000 citations. Within the measurement year of 2004 alone, it received 522 citations. Our next most cited paper from 2002-03 (concerning the functional organization of the yeast proteome) received 351 citations that year. Only 50 out of the roughly 1,800 citable items published in those two years received more than 100 citations in 2004. The great majority of our papers received fewer than 20 citations.

These figures all reflect just how strongly the impact factor is influenced by a small minority of papers - no doubt to a lesser extent in more specialized journals, but significantly nevertheless. However, we are just as satisfied with the value of our papers in the 'long tail' as with that of the more highly cited work.

The citation rate of our papers also varies sharply between disciplines. Many of Nature's papers in immunology published in 2003 have since received between 50 and 200 citations. Significant proportions of those in cancer and molecular and cell biology have been in the 50-150 range. But papers in physics, palaeontology and climatology typically achieved fewer than 50 citations. Clearly, these reflect differences in disciplinary dynamics, not in quality.

The impact factor also mixes citations to diverse types of content: unsurprisingly, review articles are typically the most highly cited, but citations of our Commentaries, News Features and News \& Views articles also contribute in a minor way to the numerator (although these items are not counted in the denominator).

The net result of all these variables is a conclusion that impact factors don't tell us as much as some people may think about the respective quality of the sci-
"Impact factors don't tell us as much as some people think about the quality of the science that journals are publishing." ence that journals are publishing. Neither do most scientists judge journals using such statistics; they rely instead on their own assessment of what they actually read.

None of this would really matter very much, were it not for the unhealthy reliance on impact factors by administrators and researchers' employers worldwide to assess the scientific quality of nations and institutions, and often even to judge individuals. There is no doubt that impact factors are here to stay. But these figures illustrate why they should be handled with caution.

\section{Toyota on a roll}

\section{Japan's approach to industrial innovation may be out of fashion, but it still delivers the goods.}

or the Japanese car company Toyota, 2005 has been a bumper year. The company's global fortunes are at such a high level that the chairman, Hiroshi Okuda, suggested back in April that it might raise its prices to give "some breathing space" to its bloated US rivals, Ford and General Motors.

The car industry isn't quite the economic driver that it was a few decades ago, but cars still account for a huge portion of consumer spending. And despite the industry's traditional conservatism, it has become a hotbed of innovation in electronics, materials, environmental engineering and other spheres.

Basic scientific research usually operates a few steps away from technological innovation in the motor industry. But Toyota is doing some interesting things at its central research and development laboratory near Nagoya (see page 1026). As in other sectors, the period of transition from scientificknowledge to industrial application is shrinking.

Toyota's success has always been more about industrial efficiency than technical innovation. But its technology has progressed steadily over the past ten years, while the competition in the United States has been resting on its laurels. Now that the boom in sales of large, conservatively designed sport utility vehicles seems to be over, US car-makers are experiencing a rude awakening.

As the prospects for the Detroit industry darkened earlier this year, credit agencies humiliated Ford and General Motors by reducing the ratings of some bonds that the two companies have issued

to 'junk' status. That apparently prompted Okuda's intervention: the Toyota chairman felt that a fresh crisis in the US car industry could lead to a surge in protectionist sentiment that might damage Toyota. Then, a few weeks ago, General Motors announced that it is planning to shed 25,000 people, almost a quarter of its factory workforce in North America.

Perhaps the starkest difference in approach between Toyota and its US rivals has been the way they tackled environmental innovation. Detroit car executives have acted like parodies of themselves, accepting generous subsidies from the federal government under then President Clinton's much-trumpeted Partnership for a New Generation of Vehicles programme and asking for less regulation in return - as though their participation was doing the

"When oil prices went through the roof last year, it was Toyota and Honda - not General Motors or Ford - who were ready at the starting gate with 'hybrid' vehicles." taxpayer a favour. That initiative came and went, but when oil prices flew through the roof last year it was the Japanese manufacturers Toyota and Honda - not General Motors or Ford - who were ready at the starting gate with their ultra-economic 'hybrid' vehicles.

Toyota's approach to science, technology and innovation isn't exactly off-the-wall. It can't afford to be: the company knows that the product has to work when it is delivered. And Toyota's scientists and engineers don't match the flamboyant modern paradigm of innovation, as inspired by California's Silicon Valley. They are, instead, meticulous, intensely loyal to the corporation, collaborative in outlook, and keen to keep a low profile. The outcome is impressive - and demonstrates that successful innovation can take many different forms. 